\title{
Prediction of Early Outcome in Ischemic Stroke in Elderly
}

\author{
Fouad MM ${ }^{1,3}$, Saad Aldin A ${ }^{1,3}$, Amin AF ${ }^{1,3}$, Alloush AT ${ }^{2,4}$, Abd Elkader RM ${ }^{2,4}$ \\ 1 Department of Neurology. Faculty of Medicine, Ain Shams University, Cairo, Egypt. \\ 2Geriatrics \& Gerontology department, Faculty of Medicine, Ain Shams University, Cairo, Egypt. \\ 3 Galaa Military hospital, Egypt \\ 4Ain Shams Ageing Research Center
}

\begin{abstract}
Background: Determining the early functional outcome of ischemic stroke is important for physicians and patients Aim: To identify the predictors of early outcome after one week from onset of ischemic stroke

Methods: A total of 85 patients with first ever ischemic stroke were divided into 2 groups, favorable and unfavorable outcome, according to the 1 -week modified Rankin scale (mRS). Favorable outcome was assumed if the score was zero to two, and unfavorable outcome if the score ranged from 3 to 6

Results: The variables associated with unfavorable outcome were high National Institute of Health Stroke Scale score on admission ( $P<0.001)$, high $m R S$ score on admission $(P<0.001)$, large volume of infarction $(P<0.001)$, presence of intracranial stenosis $(P=0.034)$, large artery atherosclerosis stroke, cardioembolic stroke and stroke of undetermined etiology $(P=0.003)$, high random blood sugar on admission $(P=0.008)$, and the occurrence of adverse events during admission period such as increase size of infarction, chest infection, symptomatic hemorrhagic transformation
\end{abstract}

Conclusions: The early outcome of ischemic stroke can be predicted by combining clinical and radiological data.

Keywords: ischemic stroke, early outcome of ischemic stroke

\section{Background:}

The prognosis after ischemic stroke has always been a concern for the patients and their families, as well as treating neurologists. This information is crucial in setting the management plan such as the need of nursing care. The predictive models depend on the clinical features and investigatory tools such as brain imaging.

Numerous variables have been identified as potential predictors of poor clinical outcome in ischemic stroke such as age ${ }^{1,2}$, severity of the clinical deficit assessed by The National Institutes of Health Stroke Scale (NIHSS) ${ }^{3,4,5}$ or modified Rankin scale (mRS) ${ }^{4}$, $\underset{8,9,10}{\text { cardiac disease }}{ }^{6,7}$, and non-lacunar stroke subtypes

This study aimed to identify the predictors of early outcome after one week from onset of ischemic stroke, relying on clinical features and investigatory tools that are commonly done in the daily practice.

Correspondence: Fouad MM: drfoash@ hotmail.com

\section{Methods}

This observational prospective hospital-based study enrolled 85 patients with the diagnosis of first ever acute ischemic stroke admitted within 24 hours of onset of symptoms. Patients were recruited consecutively after their agreement to participate in the study from the stroke unit of Ain Shams University Specialized Hospital. Diagnosis was made based on the clinical features in combination with brain imaging. All patients were subjected to the stroke protocol and underwent magnetic resonance imaging (MRI) of brain and magnetic resonance of arteries (MRA), which was visualized for the presence of intracranial arterial stenosis or occlusion. All of the patients were subjected to electrocardiogram, transthoracic echocardiography, and carotid duplex for detection of stenosis of the extra cranial carotid system.

Complete medical history was reviewed including age, gender, and vascular risk factors such as hypertension (defined as history of use of antihypertensive 
medications, or if systolic blood pressure $>140 \mathrm{mmHg}$, diastolic blood pressure $>90 \mathrm{mmHg}$, or both during admission for 4 days at least), diabetes mellitus (defined as history of use of insulin or oral hypoglycemic agents, or if blood glucose level was $\geq 126 \mathrm{mg} / \mathrm{dl}$ after an overnight fast, or if $\geq 200 \mathrm{mg} / \mathrm{dl}$ after 2 hours from ingestion of $75 \mathrm{gm}$ of oral glucose on at least 2 separate occasions).

Cardiac disease was considered if there was evidence of ischemic heart disease (such as acute myocardial infarction, angina, or coronary revascularization, low ejection fraction), atrial fibrillation, heart failure, and rheumatic heart disease. Lipid profile was withdrawn for all patients.

Stroke severity was evaluated on admission using the National Institute of Health Stroke Scale (NIHSS). Stroke subtypes were defined using the Trial of ORG 10172 in Acute Stroke Treatment (TOAST) criteriainto one of 5 categories based on risk factors as well as clinical and brain imaging features: large artery atherosclerosis, cardioembolism, small vessel occlusion (lacunar), undetermined aetiology stroke or other aetiology ${ }^{11}$.

The patients' functional status was assessed by the modified Rankin Scale (mRS) done on admission, after 24 hours from admission and at 1 -week from onset of symptoms. Favorable outcome was assumed if the mRS score was ranging from zero to 2 . If the $\mathrm{mRS}$ score was ranging from 3 to 6 , the outcome was considered unfavorable.

Patients with terminal illness and those who missed 1week follow up visit were excluded.

\section{Statistical Analysis}

The collected data were coded, tabulated, and statistically analyzed using IBM SPSS statistics (Statistical Package for Social Sciences) software version 22.0, IBM Corp., Chicago, USA, 2013.

Descriptive statistics were done for quantitative data as minimum and maximum of the range as well as mean \pm standard deviation for quantitative parametric data, median and $1^{\text {st }} \& 3^{\text {rd }}$ inter-quartile range for quantitative non-parametric data, while it was done for qualitative data as number and percentage.

Inferential analyses were done for quantitative variables using independent t-test in cases of two independent groups with parametric data and Mann Whitney $U$ in cases of two independent groups with non-parametric data. In qualitative data, inferential analyses for independent variables were done using Chi square test for differences between proportions and Fisher's exact test for variables with small expected numbers. ROC curve was used to evaluate the performance of different tests differentiate between certain groups. The level of significance was taken at $P$ value $\leq 0.05$ is significant, otherwise is non-significant.

\section{Results}

Patients were divided into two groups; group I including 54 patients with favorable outcome representing $63.5 \%$ of study population, and group II including 32 patients with unfavorable outcome representing $36.5 \%$ of study population.

Group I included 40 males and 14 females, while group II included 23 males and 8 females with no significant difference when comparing both groups. There was no significant difference between both groups when compared as regards age; the age of patients among group I were with a mean of 61.2 years while group II patients were with a mean of 65 years among $(P=$ 0.109) [Table (1)].

Table 1: Age and Gender in study population

\begin{tabular}{|c|c|c|c|c|c|}
\hline & Measure & $\begin{array}{l}\text { All } \\
(n=85)\end{array}$ & $\begin{array}{l}\text { Group } \\
\text { I } \\
(\mathrm{n}=54)\end{array}$ & $\begin{array}{l}\text { Group } \\
\text { II } \\
(n=31)\end{array}$ & $\boldsymbol{P}$ \\
\hline $\begin{array}{r}\text { Age } \\
\text { (years) }\end{array}$ & Mean & 62.6 & 61.2 & 65 & 0.109 \\
\hline \multirow[t]{2}{*}{ Gender } & Male & 63 & 40 & 23 & \multirow[t]{2}{*}{0.990} \\
\hline & Female & 22 & 14 & 8 & \\
\hline \multicolumn{6}{|c|}{ Table 2: Vascular risk factors among the study population } \\
\hline \multicolumn{2}{|c|}{ Variables } & $\begin{array}{l}\text { All } \\
(n=85)\end{array}$ & $\begin{array}{c}\text { Group I } \\
(n=54)\end{array}$ & $\begin{array}{c}\text { Group } \\
\text { II } \\
(n=31)\end{array}$ & $P$ \\
\hline \multicolumn{2}{|c|}{ DM } & $\begin{array}{l}47 \\
(55.3 \%)\end{array}$ & $\begin{array}{c}28 \\
(51.9 \%)\end{array}$ & $\begin{array}{c}19 \\
(61.3 \%)\end{array}$ & 0.400 \\
\hline \multicolumn{2}{|c|}{ HTN } & $\begin{array}{l}61 \\
(71.8 \%)\end{array}$ & $\begin{array}{c}37 \\
(68.5 \%)\end{array}$ & $\begin{array}{c}24 \\
(77.4 \%)\end{array}$ & 0.380 \\
\hline \multirow[t]{5}{*}{$\begin{array}{l}\text { Cardiac } \\
\text { diseases }\end{array}$} & Positive & $\begin{array}{l}30 \\
(35.3 \%)\end{array}$ & $\begin{array}{c}17 \\
(31.5 \%)\end{array}$ & $\begin{array}{c}13 \\
(41.9 \%)\end{array}$ & \multirow[t]{5}{*}{0.190} \\
\hline & IHD & $\begin{array}{l}21 \\
(24.7 \%)\end{array}$ & $\begin{array}{c}14 \\
(25.9 \%)\end{array}$ & $\begin{array}{c}7 \\
(22.6 \%)\end{array}$ & \\
\hline & CHF & $2(2.4 \%)$ & - & $2(6.5 \%)$ & \\
\hline & $\mathbf{A F}$ & $6(7.1 \%)$ & $3(5.6 \%)$ & $3(9.7 \%)$ & \\
\hline & $\begin{array}{c}\text { Pacemak } \\
\text { er }\end{array}$ & $1(1.2 \%)$ & - & $1(3.2 \%)$ & \\
\hline \multirow[t]{2}{*}{ Smoking } & Smoker & $23(\%)$ & $\begin{array}{c}17 \\
(31.5 \%)\end{array}$ & $\begin{array}{c}6 \\
(19.4 \%)\end{array}$ & \multirow[t]{2}{*}{0.656} \\
\hline & $\begin{array}{c}\text { Ex- } \\
\text { smoker }\end{array}$ & $8(\%)$ & $5(9.3 \%)$ & $3(9.7 \%)$ & \\
\hline
\end{tabular}


Table 3: SBP and DBP in study population

\begin{tabular}{llllll}
\hline & Measures & All $(\mathbf{n}=\mathbf{8 5})$ & Group I $(\mathbf{n}=\mathbf{5 4})$ & Group II $(\mathbf{n}=\mathbf{3 1})$ & P \\
\hline SBP $(\mathrm{mmHg})$ & Mean \pm SD & $\mathbf{1 5 0} \pm \mathbf{2 9 . 3}$ & $\mathbf{1 4 9 . 6} \pm \mathbf{3 0 . 8}$ & $\mathbf{1 5 0 . 6} \pm \mathbf{2 6 . 9}$ & $\mathbf{0 . 8 7 9}$ \\
& Range & $\mathbf{1 0 0 - 2 4 0}$ & $\mathbf{1 1 0 - 2 4 0}$ & $\mathbf{1 0 0 - 2 4 0}$ & \\
$\mathrm{DBP}(\mathrm{mmHg})$ & Mean \pm SD & $\mathbf{6 0 - 1 3 0}$ & $\mathbf{7 0 - 1 3 0}$ & $\mathbf{6 0 - 1 3 0}$ & $\mathbf{0 . 8 9 7}$ \\
& Range & $\mathbf{9 1 . 5} \pm \mathbf{1 2 . 8}$ & $\mathbf{9 1 . 7} \pm \mathbf{1 2 . 2}$ & $\mathbf{9 1 . 3} \pm \mathbf{1 3 . 8}$ & \\
\hline
\end{tabular}

Table 4: NIHSS score among study population

\begin{tabular}{|c|c|c|c|c|c|}
\hline & & $\begin{array}{l}\text { All } \\
(n=85)\end{array}$ & $\begin{array}{l}\text { Group I } \\
(n=54)\end{array}$ & $\begin{array}{l}\text { Group II } \\
(\mathrm{n}=\mathbf{3 1})\end{array}$ & $\mathbf{P}$ \\
\hline \multirow[t]{2}{*}{ NIHSS score on admission } & Range & $1-21$ & $1-19$ & $1-21$ & \multirow[t]{2}{*}{$<0.001$} \\
\hline & Mean \pm SD & $6.1 \pm 4.4$ & $4.4 \pm 3$ & $9.1 \pm 4.9$ & \\
\hline \multirow{2}{*}{$\begin{array}{c}\text { NIHSS score after } 24 \text { hours from } \\
\text { admission }\end{array}$} & Range & $0-23$ & $0-8$ & $1-23$ & \multirow[t]{2}{*}{$<0.001$} \\
\hline & Mean \pm SD & $5.7 \pm 4.6$ & $3.3 \pm 1.9$ & $9.9 \pm 5$ & \\
\hline \multirow{2}{*}{$\begin{array}{c}\text { NIHSS score at } 7 \text { days from onset } \\
\text { of symptoms }\end{array}$} & Range & $0-22$ & $0-5$ & $5-22$ & \multirow[t]{2}{*}{$<0.001$} \\
\hline & Mean \pm SD & $4.7 \pm 4.8$ & $1.5 \pm 1.4$ & $8.6 \pm 5.5$ & \\
\hline
\end{tabular}

Figure 1: Mean changes of NIHSS scores after 24 hours from admission and at 7 days from onset of symptoms

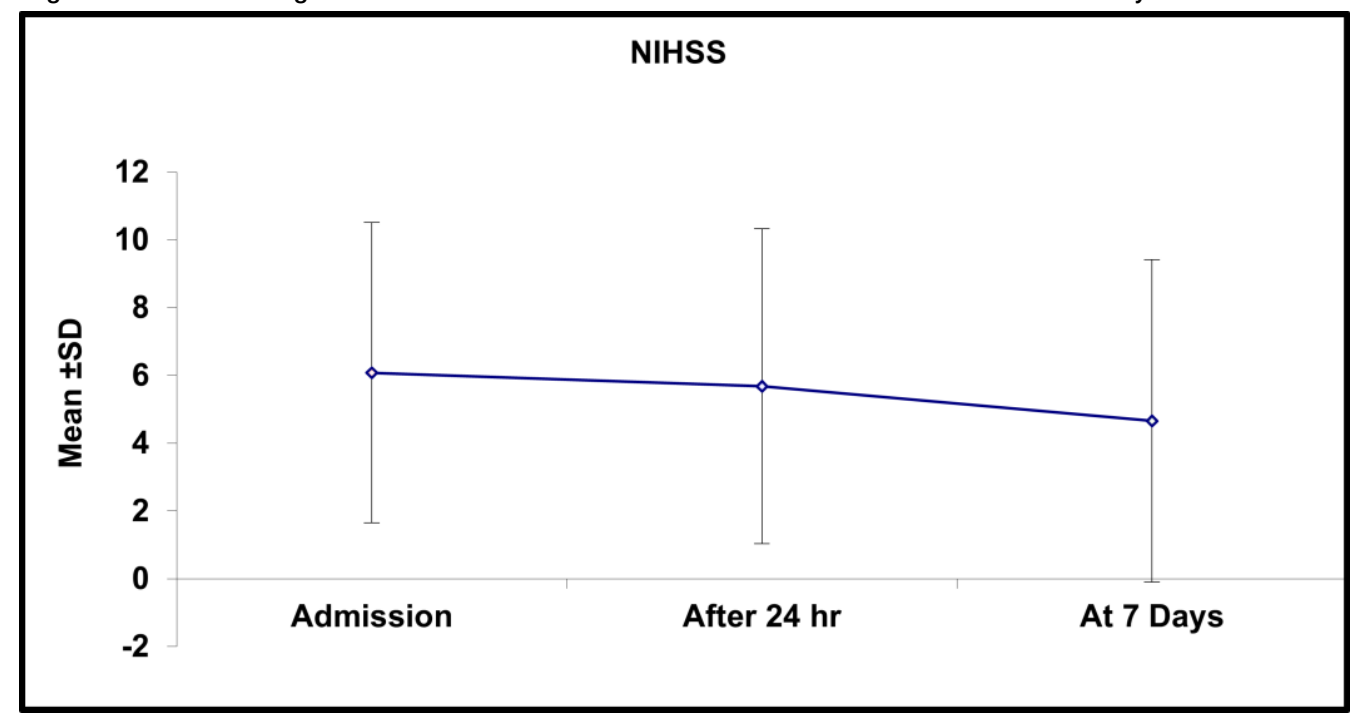

Regarding the vascular risk factors [Table (2)], diabetes mellitus was detected in 47 patients $(55.3 \%$ of study population), and there was insignificant difference between both groups as it was detected among 28 patients of group I $(51.9 \%$ of group I population) versus 19 patients among group II $(61.3 \%$ of group population $)(P=0.400)$.

Hypertension was present in 61 patients $(71.8 \%$ of study population). Hypertension was present in 37 patients of group I (68.5\% of group population) compared to 24 patients of group II $(77.4 \%$ of group population), and this was statistically insignificant ( $P=$ $0.380)$.
Cardiac diseases were present in 30 patients $(35.3 \%$ of study population) as follows; 21 patients $(24.7 \%)$ had evidence of ischemic heart disease (IHD), 6 patients (7.1\%) had AF, 2 patients $(2.3 \%)$ had congestive heart failure (CHF), one patient $(1.2 \%)$ had placed a pacemaker. Cardiac diseases were relatively more common among group II patients (13 patients representing $41.9 \%$ of group population) compared to group I patients (17 patients representing $31.5 \%$ of group population), yet this was statistically insignificant $(P=0.190)$.

Among group I patients, 17 patients $(31.5 \%)$ were smokers and 5 patients $(9.3 \%)$ were ex-smokers and among group II patients, 6 patients (19.4\%) were 
smokers and 3 patients $(9.7 \%)$ were ex-smokers. The comparison between both groups showed insignificant difference $(P=0.656)$.

As regarding the data obtained during admission, the time from the onset of symptoms till the admission to the hospital ranged from zero to 100 hours among all the study population with a mean of $20.3 \pm 22$ hours.

There was no significant difference between group I patients (ranged from zero to 99 hours with a mean of $21.5 \pm 22$ hours) and group II patients (ranged from 0.45 to 100 hours with a mean of $18.2 \pm 22.3$ hours); $\mathrm{P}$ $=0.505$.

The systolic blood pressure (SBP) at the time of admission to the hospital ranged from 100 to 240 $\mathrm{mmHg}$ among all the study population with a mean of $150 \pm 29.3 \mathrm{mmHg}$. There was no significant difference between group I patients (ranged from 110 to 240 $\mathrm{mmHg}$ with a mean of $149.6 \pm 30.8 \mathrm{mmHg}$ ) and group II patients (ranged from 100 to $240 \mathrm{mmHg}$ with a mean of $150.6 \pm 26.9 \mathrm{mmHg}) ; \mathrm{P}=0.879$.

The diastolic blood pressure (DBP) at the time of admission to the hospital ranged from 60 to $130 \mathrm{mmHg}$ among all the study population with a mean of $91.5 \pm$ $12.8 \mathrm{mmHg}$. There was no significant difference between group I patients (ranged from 70 to $130 \mathrm{mmHg}$ with a mean of $91.7 \pm 12.2 \mathrm{mmHg}$ ) and group II patients (ranged from 60 to $130 \mathrm{mmHg}$ with a mean of $91.3 \pm 13.8 \mathrm{mmHg}) ; \mathrm{P}=0.897$.

[Table (4)] shows the different score of NIHSS on admission, after 24 hours from admission, and at 7 days from onset of symptoms, while figure 1 shows the overall changes of NIHSS scores of the study population. The NIHSS score on admission ranged from 1 to 21 with a mean of $6.1 \pm 4.4$ among all the study population. Group I patients had significantly lower NIHSS scores as it ranged from 1 to 19 with a mean of $4.4 \pm 3$, compared to group II patients where it ranged from 1 to 21 with a mean of $9.1 \pm 4.9$ $(P<0.001)$.

The NIHSS score done after 24 hours from admission ranged from 0 to 23 with a mean of $5.7 \pm 4.6$ among all the study population. Group I patients had significantly lower NIHSS scores as it ranged from 0 to 8 with a mean of $3.3 \pm 1.9$, compared to group II patients where it ranged from 1 to 23 with a mean of $9.9 \pm 5$ $(P<0.001)$.

The NIHSS score done at 7 days from onset of symptoms ranged from 0 to 22 with a mean of $4.7 \pm 4.8$ among all the study population. Group I patients had significantly lower NIHSS scores as it ranged from 0 to 5 with a mean of $1.5 \pm 1.4$, compared to group II patients where it ranged from 5 to 22 with a mean of
$8.6 \pm 5.5(P<0.001)$

The comparison of the NIHSS scores of all the study population on admission to hospital and at 7 days from onset of symptoms showed that there was significant improvement of NIHSS scores at 7 days from onset of symptoms compared to the scores on admission $(P=$ $0.004)$.

The mRS scores on admission ranged from 1 to 5 with a mean of $3.4 \pm 1.4$ among all the study population. Group I patients had significantly lower mRS scores as it ranged from 0 to 2 with a mean of $0.9 \pm 0.6$, compared to group II patients where it ranged from 2 to 6 with a mean of $3.3 \pm 1.3(P<0.001)$.

Data of the MRI showed that the volume of infarction ranged from 0.125 to $240 \mathrm{~cm}^{3}$ with a mean of $14.9 \pm$ $39.1 \mathrm{~cm}^{3}$. The comparison between both groups as regards the volume of infarction, it was noticed that group II patients had larger volume of infarction (ranging from 0.5 to $240 \mathrm{~cm}^{3}$ with a mean of $33.7 \pm$ $60.2 \mathrm{~cm}^{3}$ ) compared to group I patients (ranging from 0.125 to $32 \mathrm{~cm}^{3}$ with a mean of $\left.4 \pm 6.4 \mathrm{~cm}^{3}\right)$, and this was statistically significant $(P<0.001)$ [Table (5)].

MRA data revealed that significant intracranial stenosis was present among 24 patients $(28.2 \%$ of study population). The comparison between both groups revealed that the presence of intracranial stenosis was more common among group II patients (was present among 13 patients representing $41.9 \%$ of the group population) than group I patients (was present among 11 patients representing $20.4 \%$ of the group population) and this was statistically significant $(P=0.034)$ [Table (5)].

Data of the carotid duplex showed that significant extracranial stenosis was present among 19 patients (22.3\% of study population).The comparison between both groups showed insignificant difference $(P=0.563)$ being detected in 11 patients among group I patients representing $20.4 \%$ of the group population, and in 8 patients among group II patients representing $25.8 \%$ of the group population.

The results of echocardiography revealed that the ejection fraction among the study population ranged from 15 to $80 \%$ with a mean of $63.1 \pm 11 \%$. There was no significant difference between both groups (ranging from 15 to $80 \%$ with a mean of $64.1 \pm 11.1 \%$ among group I patients versus a range from 30 to $76 \%$ with a mean of $61.3 \pm 10.9 \%$ among group II patients; $P=$ 0.258 .

Regarding the subtypes of stroke according to TOAST classification, the most common subtype of stroke was stroke due to small vessel disease (SVD); being present among 42 patients (49.4\% of study population). It was 
Table 5: MRI and MRA data of the study population

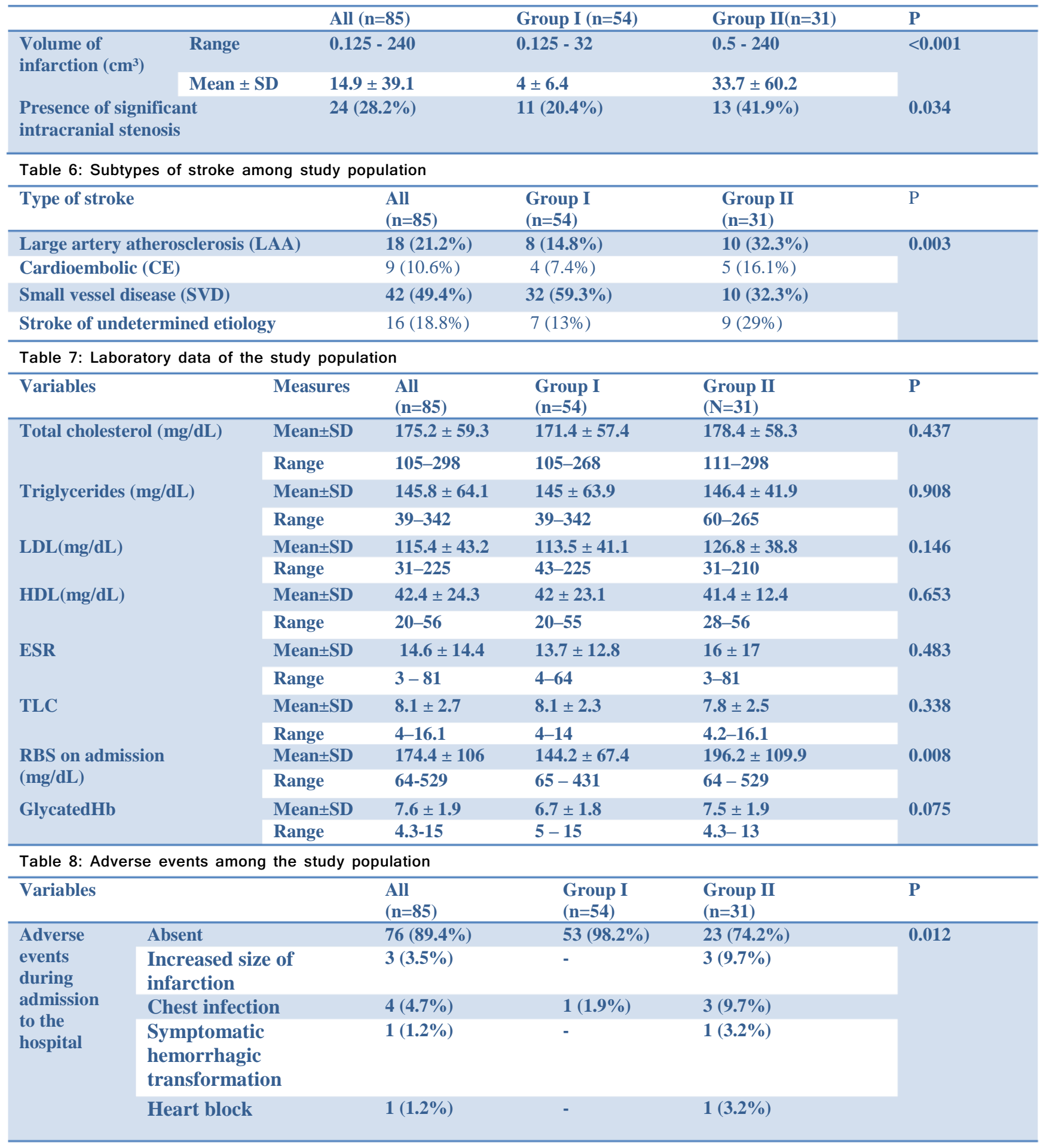


present among 32 patients of group I population $(59.3 \%$ of the group population) and among 10 patients of group II patients (32.3\% of the group population) [Table (6)].

Table (6) shows that large artery atherosclerosis (LAA) stroke was the second most common subtype and it was present among 18 patients (21.2\% of study population) It was present among 8 patients of group I population (14.8\% of the group population) and among 10 patients of group II population (32.3\% of the group population). Stroke of undetermined etiology was present among 16 patients (18.8\% of study population). It was present among 7 patients of group I population $(13 \%$ of the group population) and among 9 patients of group II population (29\% of the group population).

Cardioembolic stroke was present among 9 patients (10.6\% of study population). It was present among 4 patients of group I population (7.4\% of the group population) and among 5 patients of group II population (16.1\% of the group population).

It was noticed that LAA stroke, cardioembolic stroke, and stroke of undetermined etiology were more common among group II patients compared to group I patients, unlike the stroke due to SVD which was more common among group I patients compared to group II, with a highly significant statistical difference $(P=$ 0.003 )

As shown in [table (7)], the comparison of the laboratory results of both groups showed that the only significant difference between both groups was the random blood sugar on admission. It was shown that the serum levels of random blood sugar were significantly higher among group II patients (ranging from 64 to $529 \mathrm{mg} / \mathrm{dl}$ with a mean of $196.2 \pm 109.9$ $\mathrm{mg} / \mathrm{dl}$ ) compared to group I patients (ranging from 65 to $431 \mathrm{mg} / \mathrm{dl}$ with a mean of $144.2 \pm 67.4 \mathrm{mg} / \mathrm{dl})(P=$ $0.008)$.

As regards the adverse events that occurred during the period of admission to hospital, it was reported among 9 patients of the study population $(10.6 \%)$ as following; 3 patients $(3.5 \%)$ developed increase of the size of infarction with significant neurological deterioration, 4 patients $(4.7 \%)$ developed chest infection, one patient $(1.2 \%)$ developed symptomatic hemorrhagic transformation, and one patient (1.2\%) developed heart block with subsequent placing of pacemaker. All of these adverse events were present among group II patients except for one patient only in group I who developed an adverse event and this was statistically significant $(P=0.012)$ [Table $(8)$ ].

Regarding the reperfusion therapies that were received during admission to hospital by some patients, 13 patients $(15.3 \%$ of study population) received intravenous tPA as thrombolytic therapy and 1 patient
(1.2\%) underwent mechanical thrombectomy using Solitaire device. Among group I population, 7 patients received a reperfusion therapy $(13 \%$ of group population) and among group II population 7 patients received a reperfusion therapy $(22.6 \%$ of group population). There was insignificant difference between both groups as regards treatment with intravenous tPA $(P=0.431)$ or mechanical thrombectomy $(P=0.184)$.

Analysis of the data on discharge from hospital, it was noticed that $\mathrm{mRS}$ scores on discharge ranged from 0 to 6 with a mean of $2.3 \pm 1.6$ and the $\mathrm{mRS}$ scores at 7 days from the onset of symptoms ranged from 0 to 6 with a mean of $2.2 \pm 1.6$.

The duration of admission to the hospital ranged from 2 to 13 days among all the study population with a mean of $5.3 \pm 2.2$ days. There was no significant difference between group I patients (ranged from 2 to 9 days with a mean of $5.2 \pm 1.9$ days) and group II patients (ranged from 2 to 3 days with a mean of $5.5 \pm 2.6$ days); $P=$ 0.426 .

\section{Discussion}

The comparison between both group revealed no significant difference between both groups regarding age $(\mathrm{P}=0.109)$ of patients. Some studies supported this finding 12,13, while others found that patients with advanced age were associated with poor late outcome without statistical significant difference at 7 days ${ }^{14,15}$.

Comparing the data of both groups showed no significant differences as regards the presence of vascular risk factors such as DM $(\mathrm{P}=0.400)$, HTN $(\mathrm{P}=$ $0.380)$, presence of cardiac diseases $(\mathrm{P}=0.190)$, and smoking $(\mathrm{P}=0.656)$. Some studies found that patients with coronary artery disease and patients with pacemaker more frequently had poor late outcome without statistical significant difference at 7 days ${ }^{14,15}$, while others found that patients with long standing DM, arterial HTN and known heavy smokers had poor late outcome after ischemic stroke ${ }^{16}$. This may be due to the fact that this study aimed to determine the 7 day outcome and not the late outcome. This needs to be validated in larger scale trials studying specifically the early outcome after ischemic stroke.

It was found that unfavorable outcome was associated with high NIHSS score on admission $(\mathrm{P}<0.001)$, higher NIHSS score after 24 hours $(\mathrm{P}<0.001)$ and high NIHSS score at 7 days $(\mathrm{P}<0.001)$. Many studies supported this finding ${ }^{17,18}$ and it seems to be a reliable outcome that can predict early outcome after ischemic stroke.

High mRS score on admission was significantly associated with unfavourable outcome $(\mathrm{P}<0.001)$. This was corroborated in other studies 19,20. 
As regards MRI findings of the study population, patients with unfavorable outcome had larger volume of infarction compared to group I patients and this was statistically significant $(\mathrm{P}<0.001)$. Similar results were shown in previous studies $1,8,14$.

Intracranial stenosis was significantly associated with unfavorable outcome $(\mathrm{P}=0.034)$. Many studies concluded that intracranial stenosis was essentially associated with decreased perfusion of the brain and hence led to poor outcome in acute ischemic stroke ${ }^{21,22}$.

In one Egyptian study, symptomatic and asymptomatic intracranial arterial steno-occlusive disease were prevalent (nearly $50 \%$ of study population) and the patients with intracranial arterial steno-occlusive disease had higher NIHSS scores at admission $(\mathrm{P}=0.01)$ 23. This supports the importance of the reperfusion therapies that result in improvement of intracranial stenosis.

It was noticed that LAA stroke, CE stroke, and stroke of undetermined etiology were more commonly associated with unfavorable outcome, unlike the stroke due to SVD which was commonly associated with favorable outcome $(\mathrm{P}=0.003)$. This was corroborated in many studies ${ }^{14,24,25}$. As regards the favorable outcome associated with infarction due to SVD, this was adopted in many studies where lacunar infarcts were associated with short term good prognosis. However it seems that lacunar stroke is the early stage of small vessel disease and later on lacunar infarcts are related to a worse long term prognosis with increased risk of death, stroke recurrence and dementia. For this reason, lacunar infarction should be regarded as a potentially serious rather than a relatively benign disorder and, therefore, lacunar stroke patients require monitoring 26,27 .

The laboratory results of both groups showed that the only significant difference between both groups was the random blood sugar on admission; the high serum levels of random blood sugar were significantly associated with unfavorable outcome. This goes with the previously reported results ${ }^{28,29}$.In other study a derangement of $\mathrm{BBB}$ permeability in acute ischemic stroke, which lead to neurologic deterioration, is predicted by high serum glucose levels ${ }^{30}$. Elevated blood glucose levels provoke anaerobic metabolism, lactic acidosis, and free radical production, which in turn result in disruption of $\mathrm{BBB}{ }^{29}$.

The overall incidence of adverse events that occurred during the period of admission to hospital were significantly higher in patients with unfavorable, similar to the other studies. As regards the increase in the size of infarction that was associated with poor outcome, many studies supported this finding ${ }^{1,8}$.In this study also shows patients who developed chest infection had unfavorable outcome and this comes in agreement with many ${ }^{31,32}$.

As regarding the reperfusion therapies that were received during admission to hospital by some patients, there was insignificant difference between both groups as regards treatment with intravenous or mechanical thrombectomy. Yet this may be to the relatively small sample size of this study as the established guidelines support an established benefit of these reperfusion therapies.

The strengths of this study include the recruitment of consecutively admitted patients with acute ischemic stroke, thus allowing a homogenous stroke population and avoiding selection bias. Also the clinical criteria and the investigation modalities used in determination of the predictors of early outcome of ischemic stroke patients can be easily performed and are indeed included in the routine stroke management protocol at many hospitals. This latter issue has been our major concern as we seek to provide predictors of early outcome of ischemic stroke that are cost-beneficial, and can be applied in the daily clinical practice at our community. The limitations of this study include the relatively small sample size. It is planned to recruit more patients for verification of these results.

\section{Conclusion}

The predictors of unfavorable outcome were high NIHSS score on admission, high mRS score on admission, large volume of infarction, presence of intracranial stenosis in MRA, certain types of stroke (LAA stroke, cardioembolic stroke and stroke of undetermined etiology), high random blood sugar on admission, and the occurrence of adverse events during admission period such as increase size of infarction, chest infection, and symptomatic hemorrhagic transformation.

\section{References}

1. Weimar C, Konig IR, Kraywinkel K, et al . Age and the National Institutes of Health Stroke Scale within $6 \mathrm{~h}$ after onset are accurate predictors of outcome after cerebral ischemia: development and external validation of prognostic models. Stroke.2004; 35:158 162.

2. Andersen KK, Andersen ZJ and Olsen TS. Predictors of early and late case-fatality in a nationwide Danish study of 26,818 patients with first-ever ischemic stroke. Stroke.2011; 42:2806.

3. Liu X, LV Y, Wang B, et al. Prediction of functional outcome of ischemic stroke patients in northwest China. ClinNeurolNeurosurg. 2007: ;109(7):571-7.

4. Ovbiagele B and Saver JL. Day-90 acute ischemic stroke outcomes can be derived from early functional activity level. Cerebrovasc Dis. 2010;29(1):50-6.

5. Rost NS, Bottle A, Lee JM, et al. Stroke severity is a crucial predictor of outcome: An international prospective validation study. J Am Heart Assoc. $2016 ; 21: 5(1)$

6. Holmstrom A, Fu MLX, Hjalmarsson C, et al. Heart dysfunction in patients with acute ischemic stroke or TIA does not predict allcause mortality at long-term follow-up. BMC Neurology.2013; 13:122

7. Saposnik G, Kapral MK, Liu Y, et al. Investigators of the Registry of the Canadian Stroke Network, Stroke Outcomes Research Canada (SORCan) Working Group. Circulation.2011;123(7):739- 
49.

8. Petty GW, Brown RD Jr, Whisnant JP, et al. Ischemic stroke subtypes: a population-based study of functional outcome, survival, and recurrence. Stroke.2000; 31:1062.

9. de Jong G, van Raak L, Kessels F, et al Stroke subtype and mortality. a follow-up study in 998 patients with a first cerebral infarct. J ClinEpidemiol.2003; 56:262.

10. Lima FO, Furie KL, Silva GS, et al. Prognosis of untreated strokes due to anterior circulation proximal intracranial arterial occlusions detected by use of computed tomography angiography. JAMA Neurol.2004; 71:151.

11. Adams Jr. HP, Bendixen BH, Leira E, et al. Antithrombotic treatment of ischemic stroke among patients with occlusion or severe stenosis of the internal carotid artery: A report of the Trial of Org 10172 in Acute Stroke Treatment (TOAST) Neurology.1999;53(1):122.

12. -Muir KW, Weir CJ, Murray GD, et al. Comparison of neurological scales and scoring systems for acute stroke prognosis. Stroke.1996; 27:1817.

13. Petty GW, Brown RD Jr, Whisnant JP, et al. Ischemic stroke subtypes: a population-based study of functional outcome, survival, and recurrence. Stroke.2000; 31:1062.

14. Sumer MM, Ozdemir I and Tascilar N. Predictors of outcome after acute ischemic stroke. ActaNeurolScand.2003; 107(4):276-80.

15. Bruno A, Akinwuntan AE, Lin C, et al. Simplified modified rank in scale questionnaire: reproducibility over the telephone and validation with quality of life. Stroke.2011; 42(8):2276-9.

16. Lackland EJ Roccella AF, Myriam F, et al. Factors Influencing the Decline in Stroke Mortality: A Statement From the American Heart Association/American Stroke Association. Stroke.2014; 45:315353

17. Rost NS, Bottle A, Lee JM, et al. Stroke Severity Is a Crucial Predictor of Outcome: An International Prospective Validation Study. J Am Heart Assoc.2016; 5(1).pii: e002433.

18. Saver $\mathrm{JL}$ and Altman $\mathrm{H}$. Relationship between neurologic deficit severity and final functional outcome shifts and strengthens during first hours after onset. Stroke.2012; 43(6):1537-41.

19. Elkind MS, Sciacca R, Boden-Albala B, et al. Moderate alcohol consumption reduces risk of ischemic stroke: the northern manhattan
37, 13-19.
20. Banks $\mathrm{JL}$ and Marotta CA. Outcomes validity and reliability of the modified Rankin scale: implications for stroke clinical trials: a literature review and synthesis. Stroke.2007; 38(3):1091-1096.

21. -Ghosh M, Ghosh K, ChatterjeeA, et al. Correlation of intracranial atherosclerosis with carotid stenosis in ischemic stroke patients. Ann Indian AcadNeurol.2015; 18(4): 412-414.

22. Kim JS, Nah HW, Park SM, et al. Risk factors and stroke mechanisms in atherosclerotic stroke: intracranial compared with extracranial and anterior compared with posterior circulation disease. Stroke.2012; 43: 3313-3318

23. Moustafa RR, Abdel Moneim A, Salem HH, et al. Intracrania Steno-Occlusive Arterial Disease and its Associations in Egyptian Ischemic Stroke Patients.Stroke.2013; 44:538-54

24. Sung SF, Chen YW, Hung LC, et al. Revised iScore to predict outcomes after acute ischemic stroke.J Stroke Cerebrovasc Dis. 2014;23(6):1634-9.

25. -Ntaios G, Papavasileiou V, Makaritsis K, et al. Association of ischaemic stroke subtype with long term cardiovascular events. EurNeurol.2014; 366:991-999.

26. Arboix $A$ and Marti-Vilalta JL. Lacunar stroke.Expert Rev Neurother.2009;9(2):179-96

27. Davis SM and Donnan GA. Why lacunar syndromes are different and important. Stroke.2004; 35:1780.

28. Paciaroni M, Caso V and Agnelli G. The Concept of Ischemic Penumbra in Acute Stroke and Therapeutic Opportunities.EurNeuro.20091:61:321-330.

29. Lindsberg PJ and Roine RO. Hyperglycemia in Acute Stroke.Stroke.2004; 35:363-364.

30. Bang OY Saver JL, Alger JR, et al. Determinants of the distribution and severity of hypoperfusion in patients with ischemic stroke. Neurology.2009;71:180411

31. Chamorro A, Urra X, PlanasAM. Infection After Acute Ischemic Stroke. Stroke .2007; 38:1097-1103.

32. Suhail R, Ahmed S, Nabi S, and Iqbal M. The burden of dysphagia and chest infection in acute ischemic stroke in a tertiary care hospital of Islamabad capital territory. Pakistan Journal of Neurological Sciences. 2014; 9:4 